\title{
Medical Research Council-sumscore: a tool for evaluating muscle weakness in patients with post-intensive care syndrome
}

\author{
Zeynep Turan * D, Mahir Topaloglu and Ozden Ozyemisci Taskiran
}

\section{Dear Editor,}

COVID-19 may lead to severe acute respiratory distress syndrome requiring intensive care unit (ICU) support. Patients surviving respiratory distress could develop post-intensive care syndrome (PICS) that includes ICU-acquired weakness (ICUAW). Nearly $66 \%$ of COVID-19 patients have clinically important muscle weakness following discharge [1]. Therefore, communication between the critical care and rehabilitation physician is important to evaluate the physical function of COVID-19 survivors to start rehabilitation timely.

The comprehensive examination of muscle strength in COVID-19 is not easy. Muscle strength can be evaluated by manual muscle testing and dynamometer. Electrophysiological study is important in diagnosing critical illness neuromyopathy; however, its correlation with muscle weakness is not clear. Ultrasonography can detect atrophy and structural changes but does not correlate with muscle function [2].

Medical Research Council (MRC)-sumscore evaluates global muscle strength. Manual strength of six muscle groups (shoulder abduction, elbow flexion, wrist extension, hip flexion, knee extension, and ankle dorsiflexion) is evaluated on both sides using MRC scale. Summation of scores gives MRC-sumscore, ranging from 0 to 60 . This score was developed for detecting early strength alterations in patients with Guillain-Barré syndrome, especially who were bedridden and receiving artificial ventilation. The sensitivity and interobserver agreement of MRC-sumscore was demonstrated [3]. Despite its ceiling effect, this score reliably identifies significant

*Correspondence: drzynptrn@gmail.com

Department of Physical Medicine and Rehabilitation, Koc University School of Medicine, Maltepe Mah, Davutpasa Cad, No:4, Topkapı, Zeytinburnu, 34010 Istanbul, Turkey weakness $(<48)$ and even better in severe weakness $(<$ 36) [4] which is the main medical interest for treatment in ICUAW.

Handgrip strength is a rapid, simple, and objective tool that is measured by handheld dynamometer represents global muscle strength. The cutoff value for handgrip strength in critically ill patients is defined as $<11 \mathrm{~kg}$ force for males and $<7 \mathrm{~kg}$ force for females which is below that of the age- and sex-matched patients [5]. It was proposed as an alternative to MRC in ICUAW [5]. However, examination of other muscles by MRCsumscore might give additional information since the neurological consequences of COVID-19 are not clear yet. ICUAW is more pronounced in proximal muscles; therefore, direct evaluation of proximal muscles is also valuable. MRC is associated with mortality, hospital, and ICU-free days in ICUAW more strongly than handgrip strength [5].

In conclusion, MRC-sumscore is a valid, reliable, objective, and easy method to evaluate the global muscle strength including PICS related to COVID-19. It provides beneficial information about the clinical course. Its bedside applicability without necessitating any device makes MRC-sumscore a valuable tool in the follow-up of patients with PICS.

\section{Abbreviations \\ ICU: Intensive care unit; ICUAW: Intensive care unit acquired weakness; MRC: Medical Research Council; PICS: Post-intensive care syndrome}

\section{Acknowledgements \\ Not applicable}

\section{Authors' contributions}

ZT contributed substantially to the conception and design of the study, drafted and provided critical revision of the article, and took responsibility in necessary literature review for the study. MT contributed substantially to the conception of the study and took responsibility in necessary literature review 
for the study. OOT contributed substantially to the conception and design of the study and drafted and provided critical revision of the article. All authors read and approved the final manuscript.

\section{Funding}

No competing interest exist.

Availability of data and materials

Not applicable

Ethics approval and consent to participate

Not applicable

\section{Consent for publication}

Not applicable

\section{Competing interests}

No competing interest exist.

Received: 13 July 2020 Accepted: 11 September 2020

Published online: 18 September 2020

\section{References}

1. Wang Z, Wang Z, Sun R, Wang X, Gu S, Zhang X, et al. Timely rehabilitation for critical patients with COVID-19: another issue should not be ignored. Version 2. Crit Care. 2020;24(1):273. https://doi.org/10.1186/s13054-02002967-7.

2. Hermans $G$, Van den Berghe G. Clinical review: intensive care unit acquired weakness. Crit Care. 2015;19(1):274. https://doi.org/10.1186/s13054-015-0993-7.

3. Kleyweg RP, van der Meché FG, Schmitz PI. Interobserver agreement in the assessment of muscle strength and functional abilities in Guillain-Barré syndrome. Muscle Nerve. 1991;14(11):1103-9. https://doi.org/10.1002/mus. 880141111.

4. Hermans G, Clerckx B, Vanhullebusch T, Segers J, Vanpee G, Robbeets C, et al. Interobserver agreement of Medical Research Council sum-score and handgrip strength in the intensive care unit. Muscle Nerve. 2012;45(1):1825. https://doi.org/10.1002/mus.22219.

5. Ali NA, O'Brien JM Jr, Hoffmann SP, Phillips G, Garland A, Finley JC, et al. Acquired weakness, handgrip strength, and mortality in critically ill patients. Am J Respir Crit Care Med. 2008;178(3):261-8. https://doi.org/10.1164/rccm. 200712-18290C

\section{Publisher's Note}

Springer Nature remains neutral with regard to jurisdictional claims in published maps and institutional affiliations. 